\section{FP8 Louisiana TNTG: Two Unique Approaches to Healthier School Nutrition Environments}

Elizabeth Gollub,PhD, MPH, RD, egollub@agcenter.1su.edu, School of Nutrition and Food Sciences, LSU AgCenter, 297D Knapp Hall, Baton Rouge, LA 70803; Stephanie Jodeir, Well-Ahead Louisiana, Louisiana Department of Health; Emily Pinedam, MS, Well-Ahead Louisiana, Louisiana Department of Health; Erica Gilliam, MS, Healthy Communities Section, Louisiana Department of Education

Objective: The Louisiana Team Nutrition Training Grant program (LA TNTG) is in place to create healthier school nutrition environments and encourage healthier eating behaviors among students.

Description: The LA TNTG program is applying two unique approaches to reaching students and school communities around the state. LA TNTG has awarded a [competitive] mini-grant of $\$ 5,000$ and technical assistance to 15 schools. These resources support classroom nutrition curriculum, smarter lunchroom (SL) strategies, and creative projects or campaigns to engage students in healthier food practices. Simultaneously, in conjunction with the Louisiana Culinary Institute, LA TNTG is providing school food service professionals from these and other schools, with hands-on Culinary Training designed to improve critical food preparation skills.

Evaluation: Grade specific pre/post classroom surveys have been developed to capture change in nutrition knowledge, attitudes, and behaviors among nutrition curriculum participants. Photos and stories are being collected from schools to document their local, innovative food/nutrition projects. An initial and six-month followup Culinary skills survey was developed and is being implemented among culinary training participants to capture changes in cooking skills, food-prep knowledge, food appreciation, and attitudes toward work. Increased use of SL strategies is being measured as annual improvements on SL score cards. School production records and meal participant numbers for the 15 mini-grant schools are being tracked over the grant period to identify changes in consumption of key foods or meals. And the CDC School Health Index is being used to track change in nutrition environment over the TNTG period.

Conclusion and Implications: Still in the early stages, LA TNTG is poised to influence student eating behaviors through nutrition education, modifications to food service practices, and inspiring food-related activities. Opportunities presented through the LA TNTG could motivate long-term healthier behaviors among students, teachers, food service workers and their families.

Grant Year: 2017

\section{FP9 Improving Vegetable Selection in Middle School Lunch Through Project SELECT: Student Engagement, Lunchroom Environment, and Culinary Training}

Megan Sweat Lopes, MPH, megan.sweatlopes@maryland.gov, Maryland State Department of Education, $200 \mathrm{~W}$

Baltimore St, Baltimore, MD 21030; Sara Booker, MPH,
$R D N$, Maryland State Department of Education; Aaron Litz, $B S$, University of Maryland Baltimore; Jasmia Shropshire, $B S$, University of Maryland Baltimore; Katie Campbell, $M P H$, University of Maryland Baltimore; Chela Cooper, BA, Maryland State Department of Education; Erin Hager, PhD, University of Maryland Baltimore

Objective: To study the impact of culinary/operations and Smarter Lunchrooms training and technical assistance on the cafeteria nutrition environment and middle school students' vegetable selection.

Description: The cafeteria environment and the vegetables served to students under the National School Lunch Program can positively impact students' health and wellness. In Maryland's 2016 Team Nutrition grant, 23 middle schools were randomized to receive culinary/operations and Smarter Lunchroom training and technical assistance versus control (2:1 randomization). The culinary/operations training and technical assistance focused on maximizing efficiency and operations of vegetables and salads, vegetable cookery (roasting, steaming), and bundling vegetables with entrée items. The Smarter Lunchroom activities focused on improving the oral communication and written marketing of vegetables along service line/cafeteria and taste testing of vegetables.

Evaluation: Production records for each school for a four week period were collected each spring (baseline and follow-up). Total vegetable selection and USDA vegetable sub-group selected were analyzed. An observational audit tool (Observation School Environment Checklist, OSEC) built from the smarter lunchroom scorecard, with face validity and inter-rater reliability determined, was completed at baseline/follow-up and included observations of the cafeteria environment, focusing on meal service, menus, and the service line. The cafeteria environment was given a score in atmosphere ( $\mathrm{n}=13$ items), advertising ( $\mathrm{n}=16$ items), accessibility $(\mathrm{n}=11$ items), attractiveness ( $\mathrm{n}=4$ items), and a total score $(\mathrm{n}=44$ items).

Conclusion and Implications: The schools differ in the number of students that eat a reimbursable school lunch. Measured as the average daily participation of students, the range is 205 students to 1,000 students with the median of 471 students. Production records show, at baseline the 'starchy' vegetable overwhelmingly represents the number one selected vegetable subgroup (other subgroups include dark green, red/orange, and beans/peas/legumes, and other).

Grant Year: 2016

\section{FP10 In-Home Childcare Providers Participating in the Child and Adult Care Food Program (CACFP) Improve Knowledge and Nutritional Quality of Foods and Beverages Served with Nutrition Education Intervention}

Stephanie Schenkel,BA, MPA, schenkels2@michigan.gov, Michigan Department of Education, John A. Hannah Building, 608 W Allegan, Lansing, MI 48909; Dawn Earnesty, MS, RDN, Michigan State University Extension;

Continued on page 529 